\title{
Study of Blood Pressure during Controlled Respiration
}

\author{
Alan Murray ${ }^{1}$, Masaki Hoshiyama ${ }^{2}$ \\ ${ }^{1}$ School of Engineering, and Faculty of Medical Sciences, \\ Newcastle University, Newcastle upon Tyne, UK \\ ${ }^{2}$ Department of Education, Meisei University, Tokyo, Japan, and \\ Department of Pediatrics, The University of Tokyo \& Affiliated Hospitals, \\ Tokyo, Japan
}

\begin{abstract}
It is well known that respiration can have significant effects on blood pressure and other physiological features. However, little is known about the stability and patterns of respiration during controlled studies.

In this research we compared blood pressure, heart rate, respiration and respiration patterns during normal breathing and breathing associated with relaxation and meditation.

Continuous respiration patterns were recorded with ethical permission from normal subjects while seated, over 30-minute periods, with their blood pressure measured at the start and end of each recording period using an automated non-invasive cuff device. The same device was used for all measurements to avoid any device bias. The first set of recordings were made with no instruction on breathing technique. The subjects were then invited to an open lecture on meditation techniques, and given some additional instruction before a second similar 30-minute study period, but with no further instruction or feedback during the recording.

Comparing respiration during normal breathing with that during meditation, the average number of full respiratory cycles over the 30-minute periods fell significantly from $355 \pm 44$ (mean $\pm S D$ ) to $197 \pm 80$ $(p=0.012)$. There were no significant differences between sequential 10-minute sub-periods in either of the two study periods. The pattern of the respiration waveform during meditation was less skew $(0.18 \pm 0.20$ compared with $0.42 \pm 0.24, p=0.004)$. During normal breathing, systolic and diastolic blood pressure and heart rate fell over the 30-minute period in all subjects, but not significantly. During controlled breathing there were no consistent changes.

It is possible that the expected fall in blood pressure and heart rate during meditation was offset by the slower respiration, with the consequent depth of respiration being deeper
\end{abstract}

\section{Introduction}

There is a great deal of published information on heart rate changes in numerous clinical conditions, including for diabetes [1], heart transplant [2,3], Alzheimer's disease and vascular dementia [4], and sleep [5], as well as for studies of multifractal characteristics [6], variation over 24 hours [7], during sleep [8,9] and Zen meditation [10-12]. However, there are fewer studies on how blood pressure can be affected.

The aim of this study was therefore to analyse blood pressure changes as well as heart rate changes during normal breathing and during controlled respiration after meditation training.

This allowed the specific effect of meditation to be compared with relaxed normal breathing.

\section{Methods}

Subjects were studied over a 30-min period, and analysed for changes in respiratory pattern and blood pressure, to examine the effect of controlled respiration. In this pilot study the first 4 subjects have been fully analysed, with a total of 2208 respiratory cycles.

\subsection{Study subjects}

Subjects with no known cardiac disease were enroled, and gave ethical consent. Their ages were $44 \pm 7$ years (mean \pm standard deviation).

None of the subjects exhibited any ectopic beat during the recording periods.

\subsection{Study conditions}

Subjects were asked to sit on an office chair, while their respiratory waveform was recorded to a computer for offline analysis. For this first control recording no instruction was given on breathing techniques. After a few 
weeks, subjects were instructed briefly in Zen meditation techniques including respiratory exercise for lower abdominal muscle respiration [10], and recorded again in similar conditions.

Subjects were asked to remain seated and still, without talking for the 30 minute recording period. They switched off their mobile phone to avoid disturbance.

\subsection{Respiratory recordings}

Respiration was recorded using a magnetometer instrument [13]. The transmitter coil was taped to one side of the chest wall, and the receiver coil to the opposite side.

The output of the magnetometer was connected to an analogue-to-digital converter at a sample rate of $250 \mathrm{~Hz}$, and stored to a computer for off-line analysis. Any offset was adjusted before recording started, so that the respiration waveform sat centrally in the computer recording window. No adjustment of gain was made.

\subsection{Blood pressure measurement}

Blood pressure was measured at the start and end of each recording period using an automated non-invasive cuff device. The same device was used for all measurements to avoid any device bias.

\subsection{Blood pressure measurement}

Heart rate was measured simultaneously with noninvasive blood pressure at the start and end of each respiratory recording period.

\subsection{Data analysis}

Systolic and diastolic pressures were compared between subjects, between the start and end of the 30-minute study period, and between the initial control and meditation periods.

\subsection{Statistical analysis}

The t-test was used to analyse the data, and a $\mathrm{p}$ value of $<0.05$ was used for significance.

\section{Results}

\subsection{Respiration during the control periods and during meditation}

Figure 1 illustrates a short 2-minute recording from both normal breathing and controlled breathing, allowing both periods to be compared.

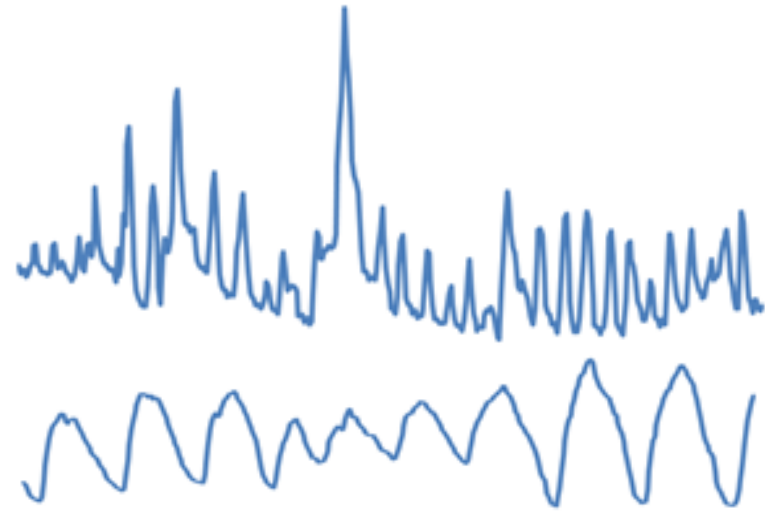

Figure 1. Examples of 2-minute extracts from the same subject. The upper section is a recording from the first, normal breathing period, acting as the control recording. The lower section is from the second period, during meditation and controlled respiration.

\subsection{Stability of respiration over the 30 - minute periods}

Figure 2 illustrates a longer section of a recording for both normal breathing and controlled breathing, again allowing both periods to be compared.
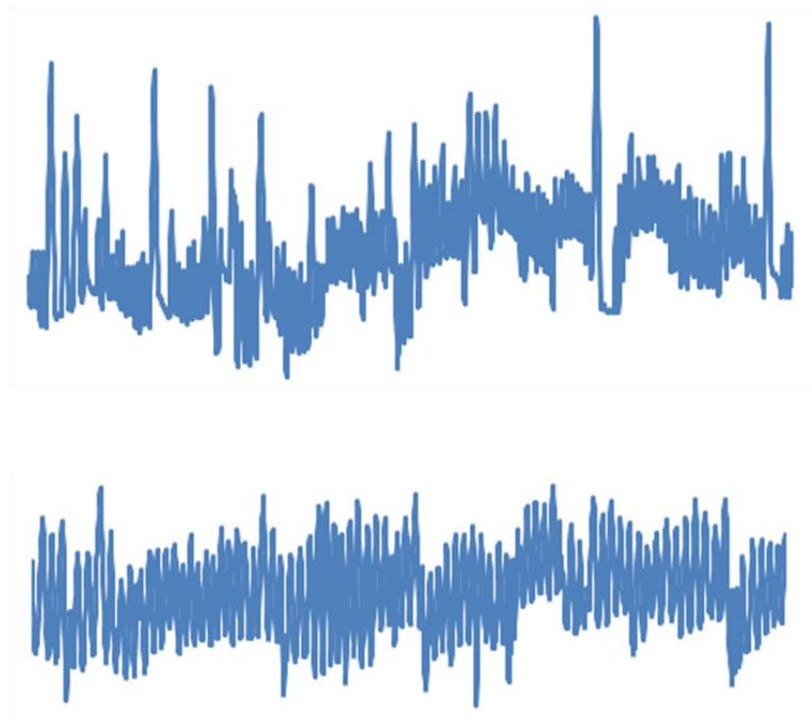

Figure 2. Examples of 10-minute extracts from the same subject. The upper section is from a recording during the normal respiration control recording, and the lower section during meditation. This extract is from the central sections of the three 10-minute sub-sections. 
There was no difference in the number of respiratory cycles between the three sequential 10-minute sections for either the control recordings or meditation recordings.

\subsection{Comparison of respiratory cycles between control periods and meditation}

Comparing respiration during normal breathing with that during meditation, the average number of full respiratory cycles over the 30-minute periods fell significantly from $355 \pm 44 \quad($ mean \pm SD) to $197 \pm 80$ $(\mathrm{p}=0.012)$.

\subsection{Comparison of respiratory patterns between control periods and meditation}

The pattern of the respiration waveform during meditation was less skew $(0.18 \pm 0.20$ compared with $0.42 \pm 0.24, \mathrm{p}=0.004$ ).

Summary results for all respiratory data are given in Table 1 .

Table 1 . Summary of respiratory results

\begin{tabular}{|l|l|l|l|}
\hline & $\begin{array}{l}\text { Normal } \\
\text { breathing }\end{array}$ & $\begin{array}{l}\text { Controlled } \\
\text { meditation } \\
\text { breathing }\end{array}$ & $\begin{array}{l}\text { Significant } \\
\text { difference }\end{array}$ \\
\hline $\begin{array}{l}\text { Number of } \\
\text { respiratory } \\
\text { cycles in } \\
\begin{array}{l}30 \text {-min } \\
\text { periods }\end{array}\end{array}$ & $355 \pm 44$ & $197 \pm 80$ & $\mathrm{p}=0.012$ \\
\hline $\begin{array}{l}\text { Average } \\
\text { respiratory } \\
\text { rate per } \\
\text { minute }\end{array}$ & $11.8 \pm 1.5$ & $6.6 \pm 2.7$ & $\mathrm{P}=0.012$ \\
\hline $\begin{array}{l}\text { Respiratory } \\
\text { waveform } \\
\text { skewness }\end{array}$ & $0.18 \pm 0.20$ & $0.42 \pm 0.24$ & $\mathrm{p}=0.004$ \\
\hline
\end{tabular}

\subsection{Comparison of blood pressure changes}

During normal breathing, systolic and diastolic blood pressure and heart rate fell over the 30-minute period in all subjects, but not significantly. During controlled breathing there were no consistent changes.

Summary results are given in Table 2.

\subsection{Comparison of heart rate changes}

A summary of heart rate changes is given in Table 2 . There were no significant changes.
Table 2. Summary results for changes in blood pressure and heart rate during the 30 -minute recording periods.

\begin{tabular}{|l|l|l|l|}
\hline & $\begin{array}{l}\text { Start of } \\
30 \text { min } \\
\text { period }\end{array}$ & $\begin{array}{l}\text { End of } \\
30 \text { min } \\
\text { period }\end{array}$ & $\begin{array}{l}\text { Significant } \\
\text { difference }\end{array}$ \\
\hline $\begin{array}{l}\text { Blood pressure } \\
\text { systolic } \\
\text { Normal respiration } \\
\text { (mmHg) }\end{array}$ & $122 \pm 5$ & $118 \pm 4$ & NS \\
\hline $\begin{array}{l}\text { Blood pressure } \\
\text { systolic } \\
\text { Controlled } \\
\text { respiration } \\
\text { (mmHg) }\end{array}$ & $124 \pm 13$ & $124 \pm 12$ & NS \\
\hline $\begin{array}{l}\text { Blood pressure } \\
\text { diastolic } \\
\text { Normal respiration } \\
\text { (mmHg) }\end{array}$ & $79 \pm 1$ & $74 \pm 10$ & NS \\
\hline $\begin{array}{l}\text { Blood pressure } \\
\text { diastolic } \\
\text { Controlled } \\
\text { respiration } \\
\text { (mmHg) }\end{array}$ & $79 \pm 7$ & $75 \pm 8$ & NS \\
\hline & $68 \pm 17$ & $65 \pm 14$ & NS \\
\hline $\begin{array}{l}\text { Heart rate } \\
\text { Normal respiration } \\
\text { (beats/min) }\end{array}$ & $74 \pm 21$ & $72 \pm 22$ & NS \\
\hline $\begin{array}{l}\text { Heart rate } \\
\text { Controlled } \\
\text { respiration } \\
\text { (beats/min) }\end{array}$ & & & \\
\hline
\end{tabular}

\section{Discussion and conclusion}

We have shown that instruction in meditation can control respiration consistently over 30 -min periods, and that subjects very significantly reduce their respiratory rate.

There was, however, no change in blood pressure or heart rate [14]. It is possible that the expected fall in blood pressure and heart rate during meditation was offset by the deeper slower respiration.

\section{Acknowledgement}

We acknowledge the support of the Great Britain Sasakawa Foundation.

\section{References}

[1] Lawrence GP, Home PD, Murray A. Repeatability of measurements and sources of variability in tests of cardiovascular autonomic function. British Heart Journal 1992;68:205-11. 
[2] Lord SW, Clayton RH Mitchell L, Dark JK, Murray A, McComb JM. Sympathetic reinnervation and heart rate variability after cardiac transplantation. Heart 1997;77:5328.

[3] Lord SW, Senior RR, Das M, Whittam AM, Murray A, McComb JM. Low-frequency heart rate variability: reproducibility in cardiac transplant recipients and normal subjects. Clinical Science 2001;100:43-6.

[4] Allan LM, Kerr SRJ, Ballard CG, Allen J, Murray A, McLaren AT, Kenny RA. Autonomic function assessed by heart rate variability is normal in Alzheimer's disease and vascular dementia. Dementia and Geriatric Cognitive Disorders 2005;19:140-4.

[5] Drinnan MJ, Allen J, Langley P, Murray A. Detection of sleep apnoea from frequency analysis of heart rate variability. Computers in Cardiology 2000;27:259-62.

[6] Ramchurn SK, Murray A. Multifractal analysis of the day and night characteristics of heart rate variability. Computers in Cardiology 2002;29:421-4.

[7] Langley P, Allen J, Bowers EJ, Drinnan MJ, Haigh AJ, King ST, Olbrich T, Smith FE, Zheng D, Murray A. The ebb and flow of heart rate variability: simulation of 24 hour heart rate time series using time series data from naturally occurring phenomena. Computers in Cardiology 2005;32:973-6.

[8] Bunde A, Havlin S, Kantelhardt JW, Penzel T, Peter JH, Voigt K. Correlated and uncorrelated regions in heart-rate fluctuations during sleep. Phys Rev Lett 2000;85:3736-9.

[9] Hoshiyama M, Hoshiyama A. Heart rate variability associated with rapid eye movements during sleep. Computers in Cardiology 2007;34:689-692.

[10] Hoshiyama M, Hoshiyama A. Heart rate variability associated with different modes of lower abdominal muscle tension during Zen meditation. Computing in Cardiology 2014; 41:773-776.

[11] Hoshiyama M, Murray A. Analysis of heart rate variability indices with slowly changing heart rate. Computing in Cardiology 2016; 43:1001-1004. doi: 10.22489/CinC.2016.289-243

[12] Hoshiyama M, Murray A. Analysis in cardiac stability over thirty minute periods. Computing in Cardiology 2017;44. doi:10.22489/CinC.2017.152-183

[13] Griffiths CJ, Gilmartin JJ, Gibson GJ, Murray A. Measurement of chest wall movement; design, performance and clinical use of a four-channel magnetometer instrument. Clinical Physics \& Physiological Measurement 1983;4:36371.

[14] Hoshiyama M, Murray A. Effects of meditation on heart rate stability. Computing in Cardiology 2018;45.
Addresses for correspondence:

Professor Alan Murray

School of Engineering, and Faculty of Medical Sciences, Newcastle University, Newcastle upon Tyne, UK.

alan.murray@ncl.ac.uk

Professor Masaki Hoshiyama,

Department of Education, Meisei University, Tokyo, Japan M.Hoshiyama@gmail.com 